Copyright $\odot 2014$

SBPjor / Associação Brasileira de Pesquisadores em Jornalismo
TRABALHAR EM UM ESPAÇO COMUNICACIONAL EM FORMAÇÃO.

\section{Facebook e Twitter como ferramentas do trabalho do community management nos sites de informação on-line sobre a Europa}

FLORIAN TIXIER

Université Libre de Bruxelles

RESUMO - Desde a criação da União Europeia, as notícias sobre a Europa têm sido um tema importante para os estudos da comunicação. Nessa perspectiva, vários sites especializados na informação sobre a Europa foram criados na primeira década do século XXI, no âmbito da constituição de uma paisagem informacional europeia na internet. No contexto das evoluções tecnológicas e econômicas do jornalismo, os jornalistas precisam rapidamente adaptar suas formas de trabalhar. Desse modo, uma nova função em termos de gestão das redes sociodigitais emerge: o community management. Esta pesquisa busca analisar os usos do Facebook e do Twitter no community management de sites de notícia sobre a Europa. De forma mais específica, vamos observar como os produtores de informação integram essas tecnologias originalmente externas ao trabalho jornalístico, e como eles usam esses novos meios de comunicação na circulação de ideias sobre a Europa, por meio de práticas de autopromoção.

Palavras-chave: Jornalismo. Redes sociais. Notícias sobre a Europa. Community management.

TRABAJAR EN UN ESPACIO COMUNICACIONAL EN DESARROLLO. Facebook y Twitter como instrumentos periodísticos de los pure-players de información europea

RESUMEN - Desde la creación de la Unión Europea, la información europea ha sido un asunto muy importante de comunicación. En los años 2000, numerosos sitios de información sobre Europa han aparecido, creando así pues un paisaje informacional europeo online, con muchos sitios pure-players (solo en línea). En un contexto de evoluciones tecnológicas y económicas que dan como resultado la aparición de nuevas técnicas de periodismo en linea, los periodistas tienen que adaptarse y vemos aflorar nuevas funciones de gestión de las redes sociales, que están designadas con la palabra inglés de community management. Esta comunicación estudia por consiguiente la utilización de Facebook y Twitter por los periodistas, mirando con precisión como los periodistas de los sitios web de información europea integran los formatos y los códigos de estos útiles que, al principio, no fueran parte de la esfera periodística, en una óptica de redacción auto-promocional de Europa.

Palabras clave: Periodismo. Redes sociales. Información europea. Community management. 
WORKING IN A DEVELOPING COMMUNICATION SPACE. Facebook and Twitter as journalistic tools for European information pure-player websites.

\begin{abstract}
Since the creation of the European Union, European information has been a very important issue of communication. Numerous Europe-specialized information websites were born in the first decade of the 21 st century, thus creating a European informational landscape on the Internet. In a context of journalistic technological and economical evolutions, journalists have to adapt rapidly their ways of working. A new function in terms of management of socio-numeric networks has appeared: community management. This research aims at analyzing the uses of Facebook and Twitter in the community management of online European information websites. We will be specifically observing how information makers integrate these technologies, which originally were not part of the journalistic work patterns, and how they use these new means of communication to circulate European ideas through self-promotion practices.

Keywords: Journalism. Social networks. European information. Community management.
\end{abstract}

O community manager pode ser, então, a versão moderna, a versão web, do secretário de redação. Ele está lá para formatar o jornal na web, se utilizando de todos os canais à sua disposição. Logo, ele se situa um pouco nessa fronteira... (Jornalista, 28 anos).

Os jornalistas sempre se utilizaram de técnicas - ferramentas materiais e tecnológicas - para praticar o seu ofício sem serem necessariamente técnicos em editoração ou programadores de informática (CORNU; RUELLAN, 1993). Pelo contrário, desenvolveram técnicas próprias ou rotinas de produção (de seleção das fontes, de enquadramento) com o objetivo de produzir certa racionalização da sua prática profissional.

Sem cair em um debate calcado no determinismo tecnológico sobre a emergência de um espaço público europeu originado a partir da emergência da internet, constata-se que a web favorece a difusão, de maneira dispersa, dos discursos e informações sobre a Europa (LE CAM; UTARD, 2011). Os anos 2000 foram particularmente marcados pelo desenvolvimento de vários sites de informação especializados na Europa, o que contribuiu para definir uma paisagem informacional europeia sobre a web.

Os pure players, por exemplo, veículos independentes dos grupos midiáticos e que publicam apenas na web, criados com o desejo de promover a Europa junto às demais e mídia e ao público, têm como grande desafio conseguir uma reputação e uma visibilidade que lhes permitam perdurar, na medida em que sua especificidade 
temática representa frequentemente uma limitação (GEORGAKAKIS; SMITH, 2004). As inovações em termos de interações, sobretudo com a explosão das redes e das mídias sociais, permite que os produtores de informação possam difundir de maneira proativa seus conteúdos.

No contexto da hiperconcorrência do mercado (CHARRON; DE BONVILLE, 2004), os jornalistas devem se adaptar e, com isso, observase a emergência de novas funções ligadas à gestão das redes sociais, designadas pelo termo community management ou social media editing. Buscamos, assim, debruçar-nos sobre a aparição de novas práticas no webjornalismo, resultado da concentração e da reapropriação de competências até então dispersas (redação, edição, difusão, promoção...) a partir do ponto de vista das evoluções tecnológicas e econômicas.

O objetivo desta pesquisa é o de analisar o uso do Facebook e Twitter no processo de community management dos sites de informação europeia. Vamos nos centrar particularmente na forma como os jornalistas integram tecnologias, originariamente externas ao meio jornalístico, a uma lógica de promoção da informação sobre a Europa por meio da difusão de suas matérias nas redes sociais.

A questão da "editorialização", ou seja, do conjunto de práticas de organização e estruturação dos conteúdos na internet, está no cerne da nossa reflexão sobre a difusão profissional de conteúdos em redes de comunicação interpessoal. E a especificidade europeia dos sites estudados permite-nos, além disso, abordar a questão do engajamento jornalístico do ponto de vista de uma estratégia mais geral de informação e de comunicação comunitária.

Para efeito da pesquisa, estudamos (por meio de entrevistas e de análise de um corpus textual) três sites pure-players especializados na Europa e representativos desse cenário na França, quais sejam: Euractiv.fr, Touteleurope.eu e Cafebabel.com. A questão da difusão ao público pelos próprios jornalistas nos parece particularmente interessante no caso dos sites analisados, na medida em que esses veículos inserem-se em uma lógica de "militância informacional europeia" (ALDRIN; DAKOWSKA, 2011) e pelo fato de que as equipes de redação e de comunicação coabitarem no interior de uma estrutura de tamanho reduzido, o que favorece o intercâmbio entre elas.

Nosso interesse insere-se em uma perspectiva neoweberiana e dedica-se à sociologia do grupo de jornalistas on-line europeus para definir qual seria a jurisdição desses trabalhadores da web, incorporados recentemente a essas novas atividades. Nesse sentido, as profissões podem ser definidas pelo estabelecimento, manutenção e defesa de um saber técnica em certo domínio de uma "expertise", 
expressa pelo termo da "jurisdição" (ABBOTT, 1988).

Como sugere Anderson (201 1), não queremos situar a autoridade e a especialidade jornalísticas como simples resultado de um conflito de jurisdições entre grupos bem definidos. Ao contrário, seguimos a linha de Latour (2012), no sentido de redes de especialidades. A sociologia e a prática jornalística parecem-nos, dessa forma, bastante úteis para a análise das rotinas de produção desenvolvidas pelos jornalistas na publicação em redes sociais e para explicar o lugar dessa difusão na economia da mídia.

Trata-se, assim, de estudar o domínio conexo das redes sociais em que as práticas jornalísticas coexistem com outras práticas comunicacionais para ver como os jornalistas integram novos códigos que estavam à margem de sua jurisdição original. Mais particularmente, pretendemos utilizar o conceito de "militância informacional" desenvolvido por Dominique Cardon e Fabien Granjon ao se referirem a "toda atividade militante que seja principalmente orientada à produção e/ou à difusão de informação" (CARDON; GRANJON, 2003, p.2), aplicando-o ao nosso estudo de caso.

Além disso, observamos uma simetria no que diz respeito à dinâmica de engajamento de nossos atores, que realizam uma atividade jornalística orientada para a produção e difusão engajada de uma informação, a qual chamamos de uma "militância de informação". Esses atores são, portanto, "agentes mobilizadores" (LAGROYE, 2002) ou "pequenos empreendedores da Europa" (ALDRIN; DAKOWSKA, 2011 ), ao agirem na web a partir de um modo de ação típica desse jornalismo que estamos estudando.

\section{CAFÉBABEL, EURACTIV ET TOUTELEUROPE : A TRÍADE DA NOTÍCIAS SOBRE A EUROPA NA FRANÇA}

A escolha dos sites analisados foi feita graças ao nosso conhecimento do meio jornalístico de informação sobre a Europa na França'. Por causa disso, conseguimos selecionar casos "ricos em informação", "o que nos permite aprender muito sobre processos que possuam importância central para a pesquisa", a fim de serem estudados em profundidade (PATTON, 1990, p.169). Daremos aqui uma apresentação sucinta dos casos selecionados

\subsection{Cafébabel:}

Cafébabel foi criado em 2001 por quatro estudantes do Institut d'Études Politiques de Strasbourg com o objetivo de "criar um espaço virtual no qual eles poderiam trocar e debater questões europeias"2. Publicado 
on-line em quatro línguas (francês, inglês, italiano e espanhol), o site marca o nascimento de um modelo original de informação "generacional", totalmente digital e sistematicamente disponível em vários idiomas.

Trata-se de uma associação que dispõe de uma rede de mais de dois mil redatores/tradutores voluntários por toda a Europa. A equipe da redação central em Paris é composta de dez pessoas, das quais quatro estão vinculadas aos cargos de: 1 ) diretor de redação 2 ) responsável pelo setor financeiro e desenvolvimento 3) gerente de projetos; 4) webmaster. Os outros seis cargos são ocupados por jornalistas, sendo três editoreschefes com contratos permanentes (para as versões em alemão, inglês e francês do site), além de três editores em regime de serviço cívico ${ }^{3}$ (versões em espanhol, italiano e polonês). Já a coordenação editorial fica a cargo da editora-chefe da versão alemã do site e a equipe conta com o apoio pontual de dois ou três estagiários.

O site é majoritariamente financiado por instituições europeias graças a subvenções de custeio obtidas junto à Comissão Europeia, no âmbito do programa "Cidadania - Europa para os cidadãos". O programa, gerido pela agência executiva "Educação, audiovisual e cultura" (EACEA), mantém várias atividades e organizações em prol da promoção de uma "cidadania europeia ativa", como a participação de cidadãos e de organizações da sociedade civil no processo de integração europeia ${ }^{4}$. Cafébabel também possui parcerias privadas (Fundação Hippocrène e Knight Fondation, entre outras) e públicas (governo da região lle-de-France, ministérios franceses).

\subsection{Euractiv ${ }^{5}$ :}

A versão francesa do site Euractiv foi lançada em 9 de maio de 2007, em Paris. Ela integra uma rede de 15 sites de informação sobre as políticas europeias, distribuídos por toda a Europa. Durante a nossa observação, em fevereiro de 2013 , a equipe do site era composta de sete funcionários e dois estagiários distribuídos entre a direção, a redação, os "parceiros e o setor de comunicação". No que se refere à direção/ comunicação, a equipe era composta por: um diretor, uma diretora de parcerias e comunicação, um gerente de projetos em comunicação e parcerias e uma encarregada de projetos de comunicação. Já na redação havia uma editora-chefe, dois jornalistas e dois estagiários de jornalismo.

O site possui quatro fontes de financiamento, que são: as empresas patrocinadoras; os membros Euractors, uma espécie de parceiros privados privilegiados aos quais o site fornece conteúdo 
informativo; a publicidade on-line; e os projetos públicos, geralmente direcionados a editais lançados por instituições da União Europeia. Em 2012, a Euractiv.fr também recebeu um financiamento no valor de 90 mil euros para o desenvolvimento do site Vigie2012 que realizou um trabalho de fact-checking de declarações emitidas por políticos franceses sobre a Europa durante a campanha presidencial.

\subsection{Touteleurope ${ }^{6}$ :}

Em 2006, a União Europeia e o Estado francês se associaram para lançar o Toute l'Europe.fr, versão on-line do Serviço de Informação sobre a Europa, com conteúdos que permitiam melhor compreender o funcionamento da União Europeia, sua história, suas ações, de uma forma lúdica e "atrativa" a cidadãos não especialistas. O setor de redação é formado por três jornalistas (uma editora-chefe e dois webredatores) auxiliados por dois estagiários. A equipe de comunicação é, por sua vez, composta por 5 pessoas: 3 responsáveis pela comunicação e parcerias, um estagiário e um community manager. O site consiste em um caso mais pedagógico, que pretende produzir uma informação acessível ao grande público e explicar as instituições de forma exaustiva, fazendo o mesmo procedimento com as notícias publicados.

O Toute l'Europe é um Agrupamento de Interesse Econômico (AIE) financiado pelo Estado francês e por diversos parceiros públicos e privados envolvidos nas questões europeias. Sua renda provém de seus integrantes (Ministério das Relações estrangeiras/Ministère des Affaires Etrangères e a empresa pública de transporte ferroviário Société Nationale des Chemins de fer Français - SNCF), da organização de eventos e da submissão de projetos a editais de fomento lançados por instituições europeias (como é o caso do ShakEUR, destinado à promoção da Europa junto a pessoas de 17 anos via Facebook).

Mesmo que esses não sejam necessariamente emanações das instituições comunitárias europeias e tenham uma linha editorial própria e independente, os sites estudados retiram parte ou a quase totalidade de seus rendimentos de forma indireta, e geralmente da UE. Eles têm a característica comum de se utilizar de editais de fomento de instituições europeias, principalmente no âmbito da Resolução do parlamento europeu sobre Jornalismo e novos meios de comunicação - criar uma esfera pública na Europa ${ }^{7}$ (adotada em 07/09/2010), que visa ao desenvolvimento de uma esfera pública europeia transnacional em parceria com as instituições de forma a 
permitir uma melhor compreensão das políticas públicas. Os "novos meios" são, assim, o centro de uma estratégia de desenvolvimento das tecnologias de informação e de comunicação digital em rede.

\section{GERIR O CONTINUUM DIGITAL DA INFORMAÇÃO}

A web subverteu a organização e as práticas jornalísticas com a aparição e o desenvolvimento, a partir de meados dos anos 1990, de sites de informação on-line e que foram obrigados a se adaptar às inovações constantes nesse domínio (DE CÉGLIE; PLEDEL, 201 1), não somente porque essas mudanças tenham, pela sua própria natureza, redefinido o estatuto profissional do jornalista, mas elas contribuíram bastante para alterar a forma como os jornalistas se pensam sobre si e pensam sua relação com o trabalho, por meio de um processo de adaptação resultante de constrangimentos e de considerações tanto socioculturais como tecnológicas (BOCZKOWSKI, 2004).

A chegada dos sites do tipo pure players no cenário informativo, nesse sentido, é particularmente interessante: as formas de produção não são as mesmas, a temporalidade adquire um caráter contínuo e a informação escapa à sua rede habitual de difusão (imprensa escrita, rádio, televisão, agências de notícias). O aparecimento das redes sociais em meados dos anos 2000 e o desenvolvimento exponencial da sua utilização marcam o crescente fenômeno de "infomediação" ou de "difusão social da informação" (REBILLARD; SMYRNAIOS, 2011; RIEDER; SMYRNAIOS, 2012). Esse processo fundamenta-se em uma interação tripartite entre uma produção e uma difusão de conteúdos, de plataformas digitais de sociabilidade (sob a forma de sites de redes sociais) e de comunidades ou reagrupamentos de internautas interessados pela notícia.

Inicialmente utilizados como serviços de comunicação privada, que permitiam transpor para o contexto on-line redes de sociabilidade já existentes, os usos do Facebook e do Twitter rapidamente ultrapassaram os limites da comunicação interpessoal ordinária para se tornarem, de certa forma, uma extensão digital do espaço público (JOUËT, 2011). Tal fenômeno de difusão interpessoal da informação não tem nada de novo, se considerarmos os estudos já clássicos sobre os fluxos de informação desenvolvidos na Universidade de Colúmbia nos anos 1950 (KATZ; LAZARSFELD, 1955). Contudo, adquirem uma nova dimensão com o continuum digital sob o qual se situa a internet e que permite a coexistência, particularmente nas redes sociais, entre espaços de publicação e de comunicação.

A adoção progressiva dessas ferramentas pelos jornalistas ocorreu 
a partir da iniciativa individual, principalmente pela utilização do Twitter (LASORSA et al., 2012). Mas também é possível observar o aparecimento de coordenadores desse tipo de utilização em uma escala maior, das estruturas midiáticas, os denominados community managers. Em nosso estudo, esses "encenadores e organizadores da conversa entre os membros de uma comunidade reagrupada em torno de uma marca, de uma empresa" (SCHÖPFEL, 2009, p.1) buscam compreender a difusão do conteúdo e aumentar a audiência de suas mídias por meio de uma presença construída nas redes sociais. Desde então, com o princípio de recomendação, as contas Facebook e Twitter dos meios de comunicação tornaram-se uma espécie de "líderes de opinião 2.0" da circulação de mensagens em espaços de bastante risco em relação aos conteúdos informativos.

Para efeito da pesquisa, em fevereiro de 2013, realizamos 10 entrevistas semiestruturadas com profissionais de informação de três sites. Eles foram questionados a partir de três eixos principais: suas práticas de utilização do Facebook, suas práticas de utilização do Twitter e a definição e o lugar ocupado pelo community management no jornalismo. Todos os nossos entrevistados definiam-se como jornalistas profissionais e reivindicavam uma abordagem jornalística sobre o seu trabalho informativo (quatro deles possuíam registro de jornalista profissional, emitido na França ou em outro país) e estavam encarregados das redes sociais dos seus veículos (em diferentes níveis) ${ }^{8}$.

Os jornalistas entrevistados estavam distribuídos da seguinte forma: 6 ocupavam um cargo de jornalista/editor, 3 eram editores-chefes e um possuía um cargo de direção. As idades variavam entre 22 e 35 anos e observamos uma correlação entre a antiguidade e o nível de responsabilidade no interior do veículo. Todos os sujeitos entrevistados possuíam um nível de educação equivalente a um mestrado, com formações em Ciência Política, Relações Internacionais, Letras e Jornalismo (em Programas de Mestrado ou em Écoles ${ }^{9}$ ). Todos eles tinham no mínimo uma experiência na imprensa local ou nacional (jornais diários, semanários, rádio, televisão, agências de notícia) na França ou em outros países (geralmente nos dois) e vários deles publicaram principalmente em sites da internet. Diferentemente dos jornalistas europeus das gerações precedentes, pouco deles tinham experiência no âmbito de instituições comunitárias em Bruxelas (dois em dez).

Em um segundo momento, realizamos uma abordagem mais quantitativa, por meio da análise da produção dessas pessoas nas contas oficiais no Facebook e no Twitter dos três veículos em questão no período de dois meses antes das entrevistas, de $1^{\circ}$ de janeiro a 28 
de fevereiro de 2013 (corpus de 731 posts e de 2.395 tweets) ${ }^{10}$. Em seguida, efetuamos uma análise temática desses dados (formato, tipo de discurso, interatividade, registro, reações). Este estudo pretende, antes de tudo, fazer uma exploração de tendências nas práticas profissionais de um grupo específico de jornalistas, já sabendo da necessidade de se fazer mais tarde uma análise mais exaustiva.

\section{UMA PRÁTICA CRONOFÁGICA}

A dispersão das práticas e a obrigação de polivalência às quais os jornalistas da web são submetidos (DATCHARY, 2010) traduzem-se na necessidade de assimilação de novos códigos com o objetivo de se adaptar à carga de trabalho, aos novos usos da mídia e inventar suas próprias formas de fazer. De fato, essas tarefas foram incorporadas à atividade jornalística no interior dos meios de comunicação e o jornalista deve encontrar uma maneira de inseri-las em sua prática profissional quotidiana.

Nessa perspectiva, a temporalidade das produções é um fator primordial para o investimento que os jornalistas farão no uso das redes sociais: a gestão do tempo no Facebook e no Twitter (sobretudo na gestão das interações percebidas pelos jornalistas como uma roda-viva interminável) e a falta crônica de tempo em um ambiente de fluxo de informações em tempo real foram espontaneamente abordadas durante nossas entrevistas. Essa pressão do tempo se traduz em termos de práticas jornalísticas por um investimento, em graus variáveis, no papel atribuído às redes sociais. Isso reflete a capacidade de o jornalista integrar, com mais ou menos facilidade, esses novos espaços às suas normas de funcionamento e ao seu trabalho cotidiano. Nossas observações nos mostraram que a publicação nas redes sociais não obedece a uma estratégia específica, mas é calculada a partir das rotinas do trabalho dos jornalistas e frequentemente em relação direta com a publicação de conteúdos no site.

Quanto ao número de posts e de tweets, é particularmente interessante por conta da "vida média" limitada das informações e se constitui em um primeiro fator representativo do modo de utilização das mídias sociais ${ }^{11}$. No início, a forma como os jornalistas se engajam nesse tipo de atividade é mínima. Isso aumenta, em seguida. E observam-se fortes diferenças, nesse ponto, entre Facebook e Twitter: as resistências são mais fortes diante da rede social de micro-blogging, que é mais recente e menos difundido na sociedade, enquanto a rede generalista Facebook já teve o tempo de se instalar como um meio de comunicação cotidiano. Além disso, os dispositivos técnicos permitem automatizar 
a redação dos posts ou dos tweets por meio de softwares de edição e facilitam o trabalho dos jornalistas, se eles assim desejaram, em sua entrada profissional, em uma rede social, realizando uma redução da carga de trabalho (sincronização da publicação nas duas contas, por exemplo). Essa observação é particularmente verdadeira no caso do Twitter, pelas razões já explicadas: perto de $30 \%$ dos tweets do nosso corpus revelam um processo de publicação automatizada.

No Facebook, esse investimento é igualmente visível na editorialização dos posts publicados: os formatos variam de algo muito simples (um texto curto ou um link) a produções mais sofisticadas (texto com conteúdo multimídia e links) ${ }^{12}$. Nesse caso, o jornalista utiliza-se de seu tempo para agregar valor à sua publicação nessas redes: a utilização de imagens de ilustração (ou mais raramente de vídeos) associadas a um conteúdo textual - o que garante certa autonomia do post em relação ao veículo de referência na medida em que ele se torna um conteúdo editado, uma espécie de "minimatéria". No caso da equipe da redação do Touteleurope, foi possível, a partir de uma reflexão sobre a estratégia de publicação em parceria com o setor de comunicação do veículo, conseguir neutralizar o constrangimento do tempo, ao delegar o trabalho de formação do conteúdo das redes sociais aos empregados da área de comunicação.

Uma etapa suplementar no tempo dedicado às redes sociais consiste na capacidade dos jornalistas de manter, ou mesmo de iniciar, interações com a comunidade de internautas. Os posts do Facebook que compõem o nosso corpus foram codificados em três itens em função do tema utilizado pelos jornalistas: informativo, para a transmissão de uma informação imparcial no formato de uma chamada curta; chamada direta, no caso de uma interpelação do leitor sob a forma de uma questão ou incitação; condescendência ou " $L O L$ ", gênero derivado do acrônimo inglês Laughing Out Loud (rindo muito alto) utilizado como gíria de internet e que consiste em se dirigir ao seu destinatário por meio de um tom de deboche ou de provocação, usando informações de duplo sentido.

Nesse cenário, vários níveis de enunciação podem coexistir em um mesmo post. Codificamos aqui até duas categorias para uma mesma produção. Um dos resultados é o fato de que o tom informativo, o mais utilizado nos veículos jornalísticos, é também majoritário no nosso corpus ( $80 \%$ dos posts). Essa prática consiste frequentemente em retomar in extenso frases da chamada ou de uma citação do artigo por meio dos recursos copiar-colar.

Além disso, observa-se certo esforço de estabelecer uma interação com o leitor, pois um quarto dos posts é classificado como 
chamada direta, o que significa que o jornalista retrabalhou a mensagem de origem sob outro formato. O "LOL", que requer um investimento mais expressivo do jornalista, é pouco utilizado. Em relação às diferenças nas linhas editoriais dos sites, a explicação provém, em grande parte, desta constatação: o aspecto muito institucional do Euractiv e a produção de informação para um público mais amplo em Touteleurope não exigem esse modo de tratamento. Já o público-alvo jovem e multicultural de Cafébabel é supostamente mais receptivo a esse tom particular.

Enfim, as menções (no Facebook e no Twitter) consistem em interpelar outro usuário da rede social incorporando ao post um link para a conta do veículo na publicação. Elas são utilizadas com um objetivo de difusão ampliada do conteúdo publicado na medida em que o post encontra-se dentro do fluxo de publicações do usuário mencionado. Essas práticas permitem, portanto, ingressar em uma lógica de rede: o jornalista apresenta seus links, insere-se em um debate permeado por conjunto de discursos e, implicitamente, perfaz sua integração em um sistema midiático de redes sociais.

Seguindo essa lógica, quanto mais o jornalista agrega valor ao seu post ou ao seu tweet, mais ele utiliza o seu tempo na produção de um conteúdo que se torna assim mais específico à rede social na qual ele difunde. O tempo à disposição dos jornalistas para realizar a comunicação de conteúdos nas redes sociais é, dessa forma, um fato primordial para a compreensão das práticas observadas. O conhecimento desses espaços e o seu controle são critérios que adquirem tanta importância que os webjornalistas podem se dar ao luxo de não se engajar nessas questões. Suas posições variam, contudo, em função da capacidade desses jornalistas em dispor do seu tempo, que será dividido com a prática jornalística "clássica".

\section{USOS JORNALÍSTICOS DAS REDES SOCIAIS: ENTRE CONSTRANGIMENTOS E LIBERDADES}

A primeira etapa referente à chegada do Facebook ou Twitter à redação é compreender os usos e normas de comunicação em vigor, caso contrário, as mensagens perdem seu valor. Esse aprendizado passa por um período de observação durante o qual o jornalista não publica nada em sua conta e se informa por meio dos numerosos artigos publicados sobre o assunto em sites especializados.

O principal constrangimento na redação para o Twitter está na própria especificidade da rede social enquanto um micro-blogging: os 
tweets não podem ultrapassar os 140 caracteres, em uma ou duas frases. Por isso, é preciso adaptar o texto a esse miniformato e encontrar os meios de transmitir a mensagem utilizando, para isso, o menor espaço possível. Tal forma reforça o imediatismo das informações publicadas e sua obsolescência quase instantânea, substituídas incessantemente por outras informações, mais frescas, mais novas, mais exclusivas.

Em relação à utilização dos hashtags é um indicador da assimilação de um dos códigos da rede. Ela corresponde ao mecanismo de colocar o sinal \# antes de uma ou mais palavras criando, dessa forma, uma palavra-chave, que será indexada pela plataforma para pesquisas temáticas. Ele também permite aos utilizadores entenderem, já num primeiro olhar, qual é o tema da mensagem. A incorporação de hashtags a um tweet significa, portanto, que o jornalista compreendeu um dos elementos básicos da comunicação no Twitter. Já a ausência do @ antes do nome de outro usuário inviabiliza qualquer tentativa de comunicação. Da mesma forma, a referência à fonte deve ser claramente indicada, sob a forma de um retweet de uma informação publicada na íntegra, ou seja, inserindo o @usuário ao final da mensagem:

\begin{abstract}
Você redige de maneiras distintas em função da rede social: no Twitter você é hiperlimitado, você tem apenas um link, por isso, publicar apenas o título pode ser uma boa divulgação; mas no Facebook se você coloca apenas o título, como a pessoa já vê o título logo abaixo da apresentação da matéria, fica feio, não atrai ninguém [...]. O valoragregado nesse caso é você adotar o seu texto à rede social. Para cada rede social é necessário redigir de uma maneira diferente, pois não é a mesma forma de se exprimir (Jornalista, 28 anos).
\end{abstract}

Analisamos aqui o caso da adaptação de uma informação de acordo com o suporte:

- Matéria: "Tsunami Grillo": a Itália nas mãos do apolitismo ${ }^{3}$

- Facebook: Eleitores italianos convertidos ao Grillo (com link incorporado: vinheta da foto do artigo, título e início da chamada).

- Twitter: Tsunami \#Grillo: a Itália nas mãos do apolitismo http://www.cafebabel.fr/ article/43566/tsunami-grillo-italie-aumain-de-a-politique.html...

No Facebook, a informação foi formatada por meio de um jogo de palavras, acompanhado do título original e da foto da matéria. Já no Twitter, tratou-se de retomar o título do artigo adicionado de um hashtag. O Facebook permite, dessa forma, ser um pouco mais criativo no texto, pois este é acompanhado do link para o artigo formatado automaticamente pela plataforma com uma foto e início de chamada: o jornalista pode, 
assim, permitir-se fazer um jogo de palavras, pois as informações principais estão visíveis logo abaixo. No Twitter, pelo contrário, a concisão do espaço disponível obriga-o a destacar a informação, nesse caso com o título, de forma que o leitor pode se perguntar sobre o que se trata. Finalmente, observa-se que cada espaço de publicação obedece às suas próprias regras, que tendem a ser interiorizadas após um período de aprendizado de um conjunto de códigos.

Tais espaços constituem ainda laboratórios de redação para os jornalistas. Eles devem levar em consideração a função de representação que exercem, afinal, eles são como a voz de seus veículos nas redes sociais. Ressalta-se, no entanto, que os jornalistas são livres na forma de escrever e difundir uma informação. Nesse sentido, normas de redação costumam ser produzidas pelas instâncias de direção e elas constituem um quadro de referência no qual o jornalista poderá exercer sua criatividade:

\footnotetext{
Eu busco fazer algo bastante pessoal. E eu respondo às pessoas que criticam o fato de que a página do Facebook não é o [nome do veículo]. Aqui, ela é mais uma página social, para a conversa e o debate, sobre coisas engraçadas, diversão. Por isso, é mais aberto, não é apenas como se fosse pro site (Jornalista, 23 anos).
}

Além disso, o jornalista está imerso em várias funções: ele pode ser, em alguns momentos, o editor, o promotor da informação, mas também o editorialista ou o mediador. Essa identidade profissional flexível e a margem de manobra pessoal na definição do seu papel nas redes sociais permite, assim, maior liberdade.

Quantos às mensagens, dois tipos principais são publicados nas redes sociais: aqueles que dizem respeito à difusão de um conteúdo produzido pelo meio (autopromocionais) e aqueles que se constituem de conteúdos informativos externos (informação e reação às notícias). No Twitter, essa segunda categoria materializa-se na forma dos retweets, retomados integralmente de uma informação partilhada por outro usuário. Se a autopromoção é um exercício definido pela própria natureza da página, a margem de manobra do jornalista reside na partilha de conteúdos externos em torno da atualidade.

Tal prática, chamada de "curadoria" (curation), permite essa abertura no nível das rotinas dos jornalistas. Derivado do inglês, a curadoria designa a princípio as atividades de conservação e valorização de um patrimônio, sobretudo nos museus. No campo da informação on-line, ela se refere à prática de acompanhamento, seleção e promoção dos links para difusão (DEGAND; GRÉVISSE, 2012).

Ao se utilizar parcial ou integralmente do seu olhar pessoal 
nessa produção, o jornalista expõem-se como indivíduo e pode orientar a linha editorial de uma página. Desse modo, Facebook e Twitter podem se tornar espaços de partilha de opiniões por parte do jornalista. Já a utilização do registro do $L O L$, mencionada logo acima, é, nesse sentido, particularmente interessante: o jornalista abandona as representações de objetividade e de neutralidade veiculadas pela profissão para tomar o papel do leitor, em um formato menos convencional, dentro do estilo ultrassubjetivo, que remete ao jornalismo gonzo.

\section{INTEGRAÇÃO DAS PRÁTICAS À MARGEM DO JORNALISMO: O APRENDIZADO DE UMA EXPOSIÇÃO DE SI}

As redes sociais integram atualmente os meios de difusão dos sites on-line e os jornalistas tiveram de aprender a realizar cotidianamente tarefas, mais ou menos básicas, necessárias à sua alimentação. A aprendizagem e a integração das rotinas de produção da informação social que decorre daí acontecem em ritmos diferentes, de acordo com o percurso dos jornalistas. Mais do que a idade, é a data de ingresso na profissão que aparece como fator determinante para o investimento dos jornalistas nas redes sociais. Os jornalistas cujas carreiras começaram antes da grande ascensão das redes sociais são, nesse caso, mais reticentes em relação ao Facebook e ao Twitter, por conta da formação e da ideia de jornalismo adquirida no decorrer da sua socialização inicial.

\footnotetext{
De fato, nós nem tínhamos mídias sociais naquela época. E então veio o momento em que era necessário ingressar no $\mathrm{FB}$, por conta da revista. Nós tivemos de votar porque éramos contra o FB. Mas isso foi nos primórdios do FB, quando ele começou a surgir. E eu me lembro de que eu não queria entrar, mas tive de fazer isso também (Jornalista, diretor de redação, 30 anos).
}

Nesse cenário, a utilização do Facebook pelos jornalistas e, em seguida, do Twitter, foi inicialmente uma ordem da direção, mas rapidamente eles tomaram gosto e passaram a utilizar cada vez mais as redes sociais na difusão da informação. Seus colegas, que chegaram mais tarde no jornalismo, nem mesmo se questionam a respeito disso. Para eles, essas ferramentas são naturais. Também não se questionam sobre a visão do jornalismo praticado.

Nesse caso, a utilização profissional das redes sociais é reforçada por uma utilização pessoal já bastante comum. Os mais jovens tinham acesso ao Facebook antes mesmo de começaram a trabalhar e a questão da proteção da vida privada (bastante forte 
dentre os jornalistas mais experimentes, que chegam a se utilizar de um pseudônimo) não tem a mesma dimensão para eles, pois o domínio do uso desses espaços é ponto passivo.

Além disso, a posição na hierarquia dos veículos também influencia os discursos dos entrevistados: as instâncias de direção têm mais tendências a aderir sem reservas, a incentivar, e mesmo a obrigar a utilização das redes sociais (sobretudo, por meio da criação de manuais de boa conduta), sucumbindo, em alguns casos, ao discurso do marketing em torno do "milagre das novas tecnologias".

Um ponto essencial parecer ser o interesse pessoal dos jornalistas nesses espaços no que diz respeito às suas consequências profissionais. Vários dentre eles acabaram destacando a necessidade de conhecer a ferramenta e de saber difundir uma imagem de si nas redes sociais elemento que integra o próprio CV do jornalista, podendo mesmo se constituir em um cartão de visitas, como acontece com o blog.

Por conseguinte, a fronteira entre o pessoal e o profissional é bem tênue e as declarações dos entrevistados reforçam a ideia de que "se é jornalista 24 horas". Eles participam, dessa forma, da constrição da mitologia profissional, ao criarem uma representação identitária do jornalista como um todo, e não apenas a de um profissional, isso graças ao continuum temporal ocasionado por Facebook e Twitter em que uma das características é justamente a exposição de uma "linha do tempo" (JEANNE-PERRIER, 2012).

No âmbito desse processo de aprendizagem e de uma autoformação pelos próprios meios, os modos de fazer são também frequentemente calcados nas práticas dos grandes veículos nacionais, bastante observados nas redes sociais. Nossos entrevistados parecem, assim, possuir uma forte consciência da importância do conhecimento e da compreensão das novas ferramentas que compõem o seu estatuto de webjornalista. Independentemente de aceitarem ou não, todos reconhecem, direta ou indiretamente, que eles devem estar atualizados no que se refere às inovações do meio digital.

Observam-se, ainda, duas dinâmicas complementares de integração das redes sociais. Em um primeiro momento, um movimento top-down, imposto pela direção: é necessário utilizar as redes sociais e se comunicar por meio delas, pois isso terá impactos positivos para o veículo. Em um segundo momento, após a fase de adequação e de aprendizado, sendo difícil em alguns casos, ocorre um movimento de bottom-up. Os jornalistas adquirem consciência da importância das mídias sociais na economia midiática e jornalística, bem como da necessidade de saberem se apresentar junto ao restante da comunidade profissional: é por meio desse fenômeno 
de branding que o veículo e os jornalistas ficam marcados nas redes sociais.

Essas redes sociais, por sua vez, permitem uma difusão e, sobretudo, uma encenação em torno da informação produzida. O principal objetivo dos jornalistas dos sites de informação especializados sobre a Europa é precisamente essa representação da região: contar histórias ao leitor, fazê-lo enxergar essa Europa e esses europeus que vivem em torno de si, mostrar a ele que as decisões tomadas em Bruxelas terão um impacto em sua vida cotidiana. É necessário conseguir vulgarizar e clarificar ao máximo as informações e as questões europeias pouco conhecidas do grande público (TIXIER, 2011 ).

Nessa perspectiva, "ser compreendido" e "ser lido" pelo maior número de pessoas exige o desenvolvimento de práticas e de técnicas particulares aos jornalistas ligados a uma especialidade (LÉVÊQUE, 2000). No caso dos jornalistas europeus, isso passa pela valorização de certo distanciamento e de um trabalho "concreto" e útil ao leitor, em oposição ao aspecto institucional e desconectado da vida cotidiana das notícias sobre a Europa.

Desse modo, pedagogia e explicações são as palavras de ordem do jornalista que fala da Europa para que o leitor não se sinta perdido em meio a uma terminologia complexa e à verborragia de caráter institucional. Essas práticas específicas da produção são ainda mais fáceis de serem aplicadas às redes sociais por conta do aspecto menos formal desses espaços, o que facilita essa prática de encenação. Seja chamando atenção para um lançamento por meio de um post que vem acompanhado de uma foto e de um link, seja fazendo uma pergunta ao leitor e convidando-o a clicar no conteúdo para ter a resposta, seja publicando uma informação intrigante de uma matéria para valorizá-la, tais técnicas buscam valorizar o conteúdo e criar no leitor o desejo de se informar sobre a Europa. Como nota Jeanne-Perrier, as redes sociais dão um destaque maior aos produtores de informação:

Os profissionais da informação viram nas redes sociais um meio de exercerem suas funções de uma maneira mais fluida, ou até mesmo de arriscarem práticas e gestos às vezes proibidos pelas empresas midiáticas. Assim, os jornalistas produzem, nas redes, um estilo que, na mídia tradicional, seria restrito a certos editorialistas (JEANNE-PERRIER, 2012, p.154).

Os jornalistas estão, portanto, mais interessados na promoção nas redes sociais de um conteúdo adaptado a um público particular do que nas interações com a comunidade de leitores. Eles ainda estão experimentando esse tipo de produção e a confrontam com suas próprias rotinas profissionais, o que dá origem a ajustes 
e adaptações, seja pela aquisição de novos códigos, seja pela transposição dos métodos de redação jornalística.

\section{DO TÉCNICO AO EDITORIAL: UM FRONT EM MOVIMENTO}

Mesmo que os jornalistas estudados tenham concretamente uma utilização diária das redes sociais e uma competência ajustada à sua prática profissional, eles tendem a guardar certa distância desses espaços. Em nossa pesquisa, todos os entrevistados estavam concordavam em dizer que o community management de um site de informação poderia ser realizado por qualquer pessoa e não apenas pelos jornalistas. No entanto, eles insistem na necessidade de haver um "faro para a notícia" (ANDERSON, 2011) e de estarem completamente integrados à equipe da redação para poder realizar corretamente esse tipo de tarefa:

O ideial seria alguém na fronteira entre essas duas [práticas]. Alguém que goste de tudo o que for ferramenta de comunicação mas que guarde um certo rigor jornalístico para saber verificar a informação [...]. Eu acho que é preciso sim, pelo menos um pouco de fibra jornalística (Jornalista, 28 anos).

Encontramos aqui a ideia de métier de fronteira (RUELLAN, 1993), por meio da definição e da integração de práticas que estão às margens do jornalismo: o community management dos sites de informação on-line encontra-se no interstício do trabalho do publicitário e do webjornalista. Nem jornalismo, nem marketing, o community management procura o seu espaço.

Originalmente tidas como ferramentas externas ao espaço jornalístico, as redes sociais foram assimiladas no interior da jurisdição dos jornalistas, tendendo a se tornar uma prática de trabalho internalizada, em vias de uma rotinização. É, sobretudo, a valorização de um tipo de tratamento editorial e das necessidades econômicas inerentes aos pequenos veículos independentes que faz com o que jornalista passe assumir tarefas anteriormente exteriores à sua especialidade. Nesse sentido, a aceitação das técnicas de community management, utilizadas no seu trabalho cotidiano, reflete as capacidades de integração dos jornalistas de práticas comunicacionais situadas à margem de sua jurisdição primária. Ao admitir um uso profissional e cotidiano das redes sociais, eles conseguem evitar ser ultrapassados por outros trabalhadores da informação.

Contudo, algumas resistências são evidenciadas - de forma mais ou menos expressiva - sobretudo no âmbito do aspecto promocional, mais 
afastado dojornalismo propriamente dito, e bastante próximo da publicidade. Assim, a valorização de um tratamento editorializado de uma atividade de difusão e de curadoria da informação permite aos jornalistas dos veículos pure players de notícias sobre a Europa superarem essa primeira dicotomia. Dessa forma, eles insistem em um tratamento qualitativo da informação e, caso isso não funcione, na partilha de uma leitura internacionalizada da informação, permitindo romper, de alguma forma, com a circulação circular das notícias no âmbito nacional (BOURDIEU, 1992).

A própria temática desses sites "europeístas" permite, assim, um elemento de respostaàs práticas dos communitymanagement. nãoéa promoção de um conteúdo que eles fazem, mas a promoção de uma causa maior, a das ideias europeias. Eles adotam uma postura simbólica que os situa no exterior de uma busca desenfreada por audiência, o que confere certa legitimidade ao seu discurso. É nesse sentido que esses atores podem ser qualificados como pequenos empreendedores da Europa, "ou seja, esses atores estatutariamente exteriores às instituições da UE, mas que estão mobilizados em torno da causa integracionista, multiplicando as iniciativas para expor, explicar, edificar a Europa e, assim, Ihe atribuir legitimidade" (ALDRIN; DAKOWSKA, 201 1, p.9).

\begin{abstract}
Pouco importa o aumento das estatísticas [de acesso]. O que nos interessa é que as pessoas passem realmente um tempo navegando no site e que leiam os nossos conteúdos. Não há nada a ser vendido, então não queremos que as pessoas cheguem por acaso no site [...]. Temos pessoas aqui, nos setores de comunicação e de redação, que querem falar da Europa, não porque isso dá visibilidade, mas porque, no fundo, isso interessa a eles. [Nome do site de informação sobre a Europa] e o [Nome do site de informação sobre a Europa] são a mesma coisa eu acho, somos todos pessoas que fazem um pouco de tudo, pois somos polivalentes e as fronteiras são relativamente frágeis (Editora-chefe, 30 anos).
\end{abstract}

Para além disso, eles adotam um militantismo de informação, trazendo para a esfera midiática a informação sobre a Europa, não sem reivindicar sua neutralidade: os jornalistas insistem no fato de que eles não são nem próeuropeus, nem eurocéticos, mas "eurocríticos", ou seja, euroentusiastas lúcidos. Para justificar essa posição, os produtores de informação investigados utilizam-se - conscientemente ou não - da explicação normativa sobre as instituições comunitárias da Europa que afirma que o déficit comunicacional e informativo da UE estaria na origem de um déficit democrático ${ }^{14}$. E isso explica a vontade de interagir com o público para deixar a Europa mais concreta, o que se tornou particularmente possível com a utilização das redes sociais.

O jornalista torna-se, dessa forma, o mediador voluntário dessa Europa política que ele deixa transparecer em sua atuação nessas mídias. A temporalidade da publicação contínua e repetitiva das redes sociais 
também participa desses aspectos. Os sites pure players de informação sobre a Europa produzem relativamente pouco conteúdo diário (se comparado a certas imagens e documentos publicados on-line pelas instituições europeias ou pelas dezenas de matérias publicadas por um veículo tradicional), o que dá às redes sociais a possibilidade de multiplicar essas produções e, dessa forma, de ocupar a esfera midiática de modo contínuo a fim de aumentar sua visibilidade.

Essas práticas de difusão de informações pelos jornalistas nas redes sociais inserem-se em um processo de infomediação social (REBILLARD ; SMYRNAIOS, 2011). Nesse sentido, os jornalistascommunity managers produzem e difundem a informação por meio das redes sociais (Facebook e Twitter) direcionadas a comunidades (fãs e followers) no contexto particular da informação on-line sobre a Europa.

Mas, contrariamente à infomediação social clássica, efetivada por meio da partilha de links e sites de informação pelos internautas, sem nenhum aporte, o jornalista exerce aqui um controle na formatação e na produção de um conteúdo adaptando-o a uma rede e a uma comunidade: ele agrega valor à informação e à própria possibilidade de uma interação. Assim, seja na adaptação do conteúdo de produção para cada um desses espaços, seja no tom adotado frente aos leitores, seja ainda na partilha do seu clipping de informações no qual ele se torna um pouco de referência, o jornalista, ao mesmo tempo editor, promotor da informação, editorialista ou mediador, vai buscar o seu público e tentar incentivar o clique.

Nesses espaços de investimento da comunicação interpessoal, o jornalista, por meio da página do seu veículo, quer, de certa forma, desempenhar o papel de um "líder de opinião 2.0" para a sua audiência: é nesse sentido que pretendemos falar aqui de uma infomediação social editorializada no âmbito dessas configurações. Um estudo subsequente poderia, assim, dedicar-se ao processo de recepção dessas mensagens pelo público com o objetivo de avaliar o seu impacto.

\section{NOTAS}

1 Ver: Tixier (201 1). O autor também trabalhou como jornalista em um site de notícias sobre a Europa, o Myeurop.info, de janeiro de 2011 a junho de 2012.

2 Disponível em: http://www.cafebabel.fr/about/history/. Acesso em: 04 abr. 2013. 
3 Espécie de contrato para que jovens com menos de 26 anos possam trabalhar, geralmente em associações. O programa é subsidiado pelo estado francês, que paga a maior parte do salário. Ver também: http://www.service-civique.gouv.fr/content/quest-ce-que-le-servicecivique\%20? Acesso em: 05 mai. 2013.

4 Disponível em: http://eacea.ec.europa.eu/citizenship/programme/ about_citizenship_fr.php. Acesso em: 13 mai. 2014.

5 Disponível em: http://www.Euractiv.fr/a-propos.html\#presentation. Acesso em: 04 abr. 2013.

6 Disponível em: http://www.Touteleurope.eu/fr/menu-rapide-haut-2/ qui-sommes-nous.html. Acesso em: 04 abr. 2013.

7 Disponível em: http://www.europarl.europa.eu/sides/getDoc. do?pubRef=-//EP//TEXT+TA+P7-TA-2010-0307+0+DOC+XML+V0// FR. Em português: http://www.europarl.europa.eu/sides/getDoc. do?pubRef=-//EP//TEXT+TA+P7-TA-2010-0307+0+DOC+XML+V0// PT. Acesso em: 13 mai. 2014.

8 No caso específico do Touteleurope, é preciso observar que a gestão da prática e da publicação on-line dos posts no Facebook é gerida pela equipe de comunicação. Essa estratégia comum foi desenvolvida conjuntamente pelos setores de comunicação e redação do site para racionalizar a produção nas redes sociais e evitar redundâncias. Os jornalistas possuem acesso a essas mídias sociais, mas eles não são responsáveis pela sua atualização no dia a dia.

9 No sistema educacional francês, as Écoles (escolas) fazem referência a estabelecimento de ensino superior que fazem o recrutamento por meio de concurso/seleção e asseguram uma informação de alto nível (Nota do tradutor).

10 Mesmo que a coleta de dados seja relativamente simples no Twitter, graças ao número de ferramentas já existentes, no caso do Facebook, é preciso realizar uma codificação manual de todos os posts publicados, o que nos levou a trabalhar com um período de análise relativamente curto.

11 Ver anexos: Tabelas 01, 02 e 03

12 Ver anexos: Tabela 04

13 Em referência a Beppe Crillo, comediante, blogueiro e político italiano, fundador do Movimento 5 Estrelas, partido que surpreendeu nas eleições 
italianas de 2013 (Nota do tradutor).

14 Sobre o assunto ver particularmente: Aldrin (2009).

\section{REFERÊNCIAS}

ABBOTT, Andrew. The System of the Professions: an essay on the division of expert labor. Chicago: University of Chicago Press, 1988.

ALDRIN, Philippe; DAKOWSKA, Dorota (Org.). Promouvoir l'Europe en actes. Une analyse des petits entrepreneurs de la cause européenne. Politique européenne, Paris, L'Harmattan, n. 34, p. 7-35, feb. 2011.

ALDRIN, P . L'Union européenne face à l'opinion. Construction et usages politiques de l'opinion comme problème communautaire. Savoir/Agir, n7, p. 13-23, 2009.

ANDERSON, C.W. What Aggregators Do: Towards a Networked Concept of Journalistic Expertise in the Digital Age. Journalism, Sage, v. 14, n. 8, p. 1008-1023, nov. 2013.

BOCZKOWSKI, Pablo. The mutual shaping of technology and society in videotex newspapers: Beyond the diffusion and social shaping perspectives. The Information Society, Taylor \& Francis, Vol. 20, n. 4, p. 255-267, jan. 2004

BOURDIEU, Pierre. Sur la télévision, Libre-Raisons d'agir, Paris, 1996

CARDON, Dominique ; GRANJON, Fabien. Peut-on se libérer des formats médiatiques ? Le mouvement alter-mondialisation et l'Internet. Mouvements, Paris, Vol. 25, n. 1, p. 67-73, 2003.

CHARRON, Jean; DE BONVILLE, Jean. Le journalisme et le marché: de la concurrence à l'hyperconcurrence. In: BRIN, Colette; CHARRON, Jean; DE BONVILLE, Jean (Org.). Nature et transformation du journalisme, Sainte-Foy (Québec), Les Presses de l'Université Laval, p. 273-316, 2004.

CORNU, Gérard; RUELLAN, Denis. Technicité intellectuelle et professionnalisme des journalistes. Réseaux, v. 11, n.62, p. 145-157, 1993.

DATCHARY, Caroline. Ce que le Web 2.0 fait à l'autonomie journalistique. L'expérience Médiapart. In : LEMIEUX, C. (Org.). La subjectivité journalistique, Editions de l'EHESS, p. 123-142, 2010.

DE CEGLIE, Audrey; PLEDEL, lannis. Journalisme classique vs cyberjournalisme: étude comparative de stratégies marketing basées sur la médiation. In: Colloque Web social, communautés virtuelles et consommation. Congrès international ACFAS, Chaire de relations publiques et communication marketing - UQAM, 79., 2011, Quebec. Acts... Canadá: Université de Sherbrooke, May 2011. 
DEGAND, Amandine ; GREVISSE, Benoit (Org). Journalisme en ligne. Pratiques et recherches. Bruxelles, De Boeck, 2012.

GEORGAKAKIS, Didier ; SMITH, Andy. Enseigner l'Europe. Politique européenne, n. 14, n³, p. 5-19, 2004.

JEANNE-PERRIER, Valérie. Journalistes et réseaux sociaux. In: DEGAND, Amandine; GREVISSE, Benoit (Org.). Journalisme en ligne. Pratiques et recherches. Bruxelles, De Boeck, p. 133-155, 2012.

JOUET, Josiane et al. Political information and interpersonal conversations in a multimedia environment : a quantitative and qualitative examination of information practices in France. European Journal of Communication, n'26, p. 361-375, 2011.

KATZ, Elihu ; LAZARSFELD, Paul. Personal influence: the part played by people in the flow of mass communications. New York: Free Press, 1955.

LAGROYE, Jacques. Sociologie Politique. Paris: Presses de Sciences Po, 2002.

LASORSA, Dominic et al. Normalizing Twitter. Journalism Studies, Vol. 13 , n. 1, p. 19-36, 2012.

LATOUR, Bernard et al. The Whole is Always Smaller Than Its' Parts: A Digital Text of Gabriel Tarde's Monad. British Journal of Sociology, Vol. 63, n4, p. 590-615, dec. 2012.

LE CAM, Florence ; UTARD, Jean-Michel. Parler(s) d'Europe sur le Web. Cafebabel ou les énonciations dispersées d'une parole européenne. Politique européenne, Vol. 34, n², p. 63-93, 2011.

LÉVÊQUE, Sandrine. Les Journalistes sociaux. Histoire et sociologie d'une spécialité journalistique. Rennes, PUR, 2000.

PATTON, Michael. Qualitative evaluation and research methods. Beverly Hills, CA: Sage, 1990.

REBILLARD, Franck; SMYRNAIOS, Nikos. Entre coopération et concurrence: Les relations entre infomédiaires et éditeurs de contenus d'actualité. Concurrences, n. 3, p. 7-18, 2011.

RIEDER, Bernard; SMYRNAIOS, Nikos. Pluralisme et infomédiation sociale de l'actualité: le cas de Twitter. Réseaux, Vol. 176, n6, p. 105-139, 2012.

RUELLAN, Denis. Le professionnalisme du flou. Grenoble, PUG, 1993.

SCHOPFEL, Joachim. Animer le web 2.0. Archives ouvertes, @rchivesIC, Centre pour la communication scientifique directe, hdl:10670/1.rnau0n, 2009.

TIXIER, Florian. Parler d'Europe: enjeux et défis d'une nouvelle spécialité journalistique. Paris: Mémoire (Master en Science Politique), Université Paris 1 Panthéon-Sorbonne, 2011. 
ANEXOS

Tabela 1 Dados gerais das contas no Facebook e Twitter

\begin{tabular}{|c|c|c|c|c|c|c|c|}
\hline \begin{tabular}{|c|}
$\begin{array}{c}\text { Nome da página } \\
\text { no Facebook }\end{array}$ \\
\end{tabular} & Data de criação & $\begin{array}{l}\text { Número de } \\
\text { curtidas }\end{array}$ & $\begin{array}{c}\text { Nome da conta } \\
\text { no Twitter }\end{array}$ & $\begin{array}{l}\text { Data de } \\
\text { criação }\end{array}$ & $\begin{array}{l}\text { Número } \\
\text { de Tweets }\end{array}$ & $\begin{array}{l}\text { Número de } \\
\text { Seguidores }\end{array}$ & $\begin{array}{c}\mathrm{N}^{\circ} \text { de contas } \\
\text { seguidas }\end{array}$ \\
\hline \begin{tabular}{|l} 
Euractiv.fr \\
\end{tabular} & $09 / 05 / 2007$ & 2185 & @EuractivFR & \begin{tabular}{|l|}
$17 / 02 / 2009$ \\
\end{tabular} & 14425 & 9983 & 1048 \\
\hline Touteleurope Ue & \begin{tabular}{|l|}
$13 / 09 / 2007$ \\
$02 / 05 / 2011$
\end{tabular} & 4855 & @Touteleurope & $16 / 02 / 2009$ & 14168 & 12095 & 1307 \\
\hline $\begin{array}{l}\text { cafebabel.com, } \\
\text { the European } \\
\text { Magazine }\end{array}$ & $23 / 11 / 2009$ & 4320 & $\begin{array}{l}\text { @cafebabel_ } \\
\text { ENG }\end{array}$ & $12 / 01 / 2010$ & 2802 & 2524 & 1797 \\
\hline $\begin{array}{l}\text { Cafebabel.com, } \\
\text { le magazine } \\
\text { européen }\end{array}$ & $29 / 03 / 2011$ & 1112 & @cafebabel_FR & $01 / 04 / 2010$ & 3395 & 1634 & 379 \\
\hline \begin{tabular}{|l|} 
Cafebabel. \\
com, das \\
Europamagazin \\
\end{tabular} & $29 / 03 / 2011$ & 553 & @cafebabel_DE & $01 / 04 / 2010$ & 1034 & 339 & 259 \\
\hline $\begin{array}{l}\text { Cafebabel. } \\
\text { com, magazyn } \\
\text { europejski }\end{array}$ & $29 / 03 / 2011$ & 412 & $\begin{array}{l}\text { @cafebabel_ } \\
\text { POL }\end{array}$ & $08 / 04 / 2010$ & 784 & 105 & 54 \\
\hline $\begin{array}{l}\text { Cafebabel. } \\
\text { com, la revista } \\
\text { europea }\end{array}$ & $30 / 03 / 2011$ & 610 & @cafebabel_ES & $08 / 04 / 2010$ & 2039 & 249 & 791 \\
\hline $\begin{array}{l}\text { Cafebabel.com, } \\
\text { la rivista europea }\end{array}$ & $30 / 03 / 2011$ & 1139 & @cafebabel_IT & $08 / 04 / 2010$ & 1237 & 893 & 526 \\
\hline
\end{tabular}

Tabela 2 Dados das contas no Twitter no período analisado

\begin{tabular}{|l|c|c|c|c|c|c|}
\hline & Cafébabel.de & Cafébabel.com & Cafébabel.es & Cafébabel.fr & Euractiv & Touteleurope \\
\hline Tweets & 71 & 261 & 122 & 514 & 896 & 531 \\
\hline Tweets/dia & 1,2 & 4,42 & 2,07 & 8,71 & 15,19 & 9 \\
\hline Menções & 47 & 40 & 23 & 176 & 379 & 146 \\
\hline$\%$ Menções & 66 & 15 & 19 & 34 & 42 & 27 \\
\hline Links & 74 & 212 & 94 & 294 & 377 & 135 \\
\hline Links /Tweet & 1 & 0,8 & 0,8 & 0,6 & 0,4 & 0,25 \\
\hline Retweets & 0 & 51 & 6 & 52 & 9 & 14 \\
\hline$\%$ retweets & 0 & 20 & 5 & 10 & 1 & 3 \\
\hline Respostas & 0 & 28 & 13 & 34 & 18 & 64 \\
\hline$\%$ respostas & 0 & 11 & 11 & 7 & 2 & 12 \\
\hline Hashtags & 38 & 0 & 210 & 135 & 877 & 602 \\
\hline Hashtags/tweet & 0,5 & 0 & 1,7 & 0,25 & 0,9 & 1,1 \\
\hline Tweets retuitados & 8 & 143 & 38 & 124 & 644 & 258 \\
\hline $\begin{array}{l}\text { Número total de } \\
\text { retweets }\end{array}$ & 11 & 206 & 48 & 217 & 1851 & 522 \\
\hline
\end{tabular}

Tabela 3 Dados das contas no Facebook no período analisado

\begin{tabular}{|l|c|c|c|c|c|c|c|}
\hline & Euractiv & Cafébabel.fr & Cafébabel.de & Touleurope & Cafébabel.es & Cafébabel.com & Total \\
\hline Número de posts & 34 & 92 & 116 & 122 & 157 & 210 & $731^{*}$ \\
\hline Posts / dia & 0,8 & 2,1 & 2,6 & 2,8 & 3,6 & 4,8 & $2,7^{* *}$ \\
\hline Número de links & 33,0 & 33,0 & 81,0 & 112,0 & 98,0 & 187,0 & $544,0^{*}$ \\
\hline Links / post & 1,0 & 0,4 & 0,7 & 0,9 & 0,6 & 0,9 & $0,8^{* *}$ \\
\hline
\end{tabular}

*: Média / **: mediana 
Tabela 4 Formato dos posts no Facebook (em números absolutos e \% da produção)

\begin{tabular}{|c|c|c|c|c|c|c|}
\hline & Texto apenas & Texto + link & Texto + foto & Texto + foto + link & Outro & $\begin{array}{c}\text { Número total } \\
\text { de posts }\end{array}$ \\
\hline Cafebabel.com & 5 & 179 & 17 & 5 & 4 & 210 \\
\hline$\%$ & 2 & 85 & 8 & 2 & 2 & 100 \\
\hline Cafebabel.fr & 28 & 28 & 26 & 4 & 6 & 92 \\
\hline$\%$ & 30 & 30 & 28 & 4 & 7 & 100 \\
\hline Cafebabel.es & 2 & 71 & 45 & 22 & 17 & 157 \\
\hline$\%$ & 1 & 45 & 29 & 14 & 11 & 100 \\
\hline Cafebabel.de & 2 & 61 & 30 & 16 & 7 & 116 \\
\hline$\%$ & 2 & 53 & 26 & 14 & 6 & 100 \\
\hline Euractiv.fr & 1 & 33 & 0 & 0 & 0 & 34 \\
\hline$\%$ & 3 & 97 & 0 & 0 & 0 & 100 \\
\hline Touteleurope.eu & 1 & 9 & 7 & 91 & 14 & 122 \\
\hline$\%$ & 1 & 7 & 6 & 75 & 11 & 100 \\
\hline Total & 39 & 381 & 125 & 138 & 48 & 731 \\
\hline $\begin{array}{c}\text { Distribuição do } \\
\text { total (mediana) }\end{array}$ & 5 & 52 & 17 & 19 & 7 & 100 \\
\hline
\end{tabular}

Tabela 5 Tipo de mensagem deixada nos posts (em números absolutos e \% da produção)

\begin{tabular}{|c|c|c|c|c|c|}
\hline & $\begin{array}{c}\text { Pedido para } \\
\text { contribuição }\end{array}$ & $\begin{array}{c}\text { Informação/ reação } \\
\text { sobre as notícias }\end{array}$ & Autopromoção & Outros & Total \\
\hline Cafébabel.com & 13 & 16 & 135 & 46 & 210 \\
\hline$\%$ & 6 & 8 & 64 & 22 & 100 \\
\hline Cafébabel.fr & 2 & 50 & 35 & 5 & 92 \\
\hline$\%$ & 2 & 54 & 38 & 5 & 100 \\
\hline Cafébabel.es & 9 & 57 & 84 & 7 & 157 \\
\hline$\%$ & 6 & 36 & 54 & 4 & 100 \\
\hline Cafébabel.de & 11 & 20 & 65 & 20 & 116 \\
\hline$\%$ & 9 & 17 & 56 & 17 & 100 \\
\hline Euractiv & 0 & 0 & 34 & 0 & 34 \\
\hline$\%$ & 0 & 0 & 100 & 0 & 100 \\
\hline Touteleurope & 0 & 20 & 100 & 2 & 122 \\
\hline$\%$ & 0 & 16 & 82 & 2 & 100 \\
\hline Total & 37 & 157 & 451 & 86 & 731 \\
\hline$\%$ & 4,9 & 22,4 & 61,9 & 10,8 & 100 \\
\hline
\end{tabular}

Florian Tixier Doutorando em Ciências da Informação e Comunicação e professor assistente na Ecole Universitaire de Journalisme da Université Libre de Bruxelles (ULB, Bélgica). E-mail: Florian.Tixier@ulb.ac.be 